\title{
Peeling the Onion. An ExPloRation OF the LAYERS OF SOCIAL INNOVATION ECOSYSTEMS \\ Modelling a context sensitive perspective on driving and hindering factors for social innovation
}

\author{
Christoph Kaletka \\ TU Dortmund University, Germany \\ Mona Markmann \\ TU Dortmund University, Germany \\ Bastian Pelka \\ TU Dortmund University, Germany
}

\begin{abstract}
This article builds on the emerging discourse on "ecosystems of social innovation" and develops a model to identify and analyse driving and hindering factors for social innovation initiatives. Social innovation - especially in the context of social entrepreneurship - is increasingly gaining momentum in the European welfare landscape. That growing importance challenges the scientific discourse as it asks for criteria of how to support, foster and sustain social innovation. This article utilizes two case studies illustrating different levels of drivers and barriers and develops a model for understanding contexts of social innovation. Four interrelated context levels are identified which constitute social innovation ecosystems: actors, structures, functions, and norms. The "onion"-model can be used by social innovators, financiers and policy makers alike in order to better and more strategically support social innovations themselves and to improve the framework conditions promoting or impeding them. The model allows for a better understanding of the diversity of supporting and hindering factors initiatives can face in any given urban or national social innovation ecosystem.
\end{abstract}

Keywords: Social Innovation, Social Entrepreneurship, Ecosystem, Context Sensitivity, Case Study.

\section{Introduction}

'Social innovation' is a term that almost everyone likes, but nobody is quite sure of what it means.

$\mathrm{T}$ This statement by Eduardo Pol and Simon Ville (2009: 12) exemplifies the challenge occurring when dealing with the topic of social innovation: As it appears cumulatively in a variety of different societal sectors, there are many different understandings of the term and its characteristics.

Following practice theory, social innovation can be regarded as a driver of social change. With recourse to Gabriel Tarde, a classic exponent of a sociology of innovation, Jürgen Howaldt, Ralf Kopp and Michael Schwarz (2015) regard social change as a bottom-up process, emerging by the imitation of social practices. Following this perspective, an innovation is understood as an invention which is socially diffused by practices of imitation and adaptation to new contexts:

\begin{abstract}
an innovation is therefore social to the extent that it, conveyed by the market or "non/without profit", is socially accepted and diffused widely throughout society or in certain societal subareas, transformed depending on circumstances and ultimately institutionalized as new social practice or made routine. (Howaldt and Schwarz, 2010: 26)
\end{abstract}

In consequence, an innovation does not necessarily have to exhibit benevolent characteristics to qualify as a social innovation. However, social 
innovation is often associated with solutions to societal challenges when it comes to the practical application and common understanding of the term (Phills et al., 2008). As the outcomes of social innovation are often ambivalent, its scientific exploration requires a preferably non-normative approach of looking at and analysing social innovations throughout their life cycle, since any given social innovation, its direct effects and repercussions may be assessed differently by social groups, strata, or generations.

While this generic approach is well suited to cover and describe the diversity of social innovation in different societal sectors as we see it today (Howaldt et al., 2016), we also see research areas emerging which do not cover social innovation as a whole, but "specific sub-sets of social innovations" (Kaletka and Pelka, 2015: 202), focusing on sectors (public sector innovation, corporate social innovation), geographical levels (urban social innovation), key drivers (digital social innovation, although digitalization can also be an objective), or target groups. The focus of this paper is on those social innovations which aim to contribute to the empowerment of vulnerable groups of society. Hence, we are looking at those social practices that "transcend established institutional contexts with the effect of empowering and (re)engaging vulnerable groups either in the process of the innovation or as a result of it" (Rehfeld et al., 2015: 1). This has also been the focus of SIMPACT, a project funded in the $7^{\text {th }}$ Framework Programme of the European Union, with its main objective to investigate the economic underpinnings for social innovation for vulnerable target groups. It refers to social practices as prerequisites for social change while distinctly emphasizing the relevance of their institutional context.

SIMPACT's preliminary research indicates that social innovation seems to be largely contextdependent: "The high level of dependency of SI on its context indicates that obstacles and resistance to SI are primarily coming from the conflict between the culture of the context and the new culture that SI brings with it" (Terstriep et al., 2015: 92). The authors introduce empirically rich insights into the multiple layers of influence and dependency between a social innovation and its context:

(...) our empirical research shows that it also includes both a reactive and a proactive dimension: social innovators configure their innovations as remedies to the inefficiencies or the lack in public and private provisions (reactive attitude), but they also strive to find new opportunities and to generate new products, processes, and partnerships (proactive attitude). Their proactive behaviour seems to be tightly connected with the "mission driven" nature of SI: social innovators are extremely motivated and display a strong commitment, corroborating their capacity to face difficulties and overcome obstacles. (75).

The context variables of social innovation Terstriep et al. (2015) reveal include the roles of actors, their objectives and capabilities and skills, their working style and modes of governance, the relation between "new" and "existing" solutions relevant for the social innovation, the influence of local contexts like neighborhoods, social settings and infrastructures, legal frameworks, resources, gatekeepers of societal systems and sub-systems, institutions, and several others. These highly differing framework conditions which, in combination, define the social innovation ecosystem, influence the character of social innovations, their design, actor constellations, scaling pathways and chances for sustainability. Therefore, it is widely accepted that it is impossible to take a social innovation which works in one context and simply replicate it in another. On the contrary, a new solution for the same challenge might look completely different under different circumstances and, in any case, requires thorough context sensitivity. What is needed is a model which describes these different contexts of social innovation ecosystems, a model that is both capable of organizing and analyzing drivers and barriers of social innovations on different layers, and which is thereby instructive also for the actors involved.

\section{A system of drivers and barriers}

The policy discourse on social innovation is challenged by the question of how to efficiently develop social innovations in practice fields and how to address supporting and hindering factors (e.g. European Commission, 2013; European AntiPoverty Network, 2016). In the scientific debate, the social innovation ecosystems approach has already helped to make the notion of environment for social innovations more prominent (e.g. Sgaragli, 2014; Bekkers and Homburg, 2007; Bason, 2010; Osborne and Brown, 2011; Hansson et al., 2014) - strongly linked to the diversity of understandings of 'social innovation' (Rüede and Lurtz, 2012). This is especially important regarding the question of how social innovations diffuse or scale, why one out of one hundred inventions flourishes, and why 99 do not. Concepts of social innovation ecosystems mostly differ in their understanding of said environment. They comprise 
different attributes such as the geographical level on which the ecosystem unfolds (Unceta et al., 2016), the notion of ecosystems as "seedbeds" of innovation or an actor constellation perspective expressed in the triple and quadruple helix (see Wallin, 2010; Carayannis and Campbell, 2012).

Following Tarde, we focus on the social embeddedness of inventions in a dense network of imitation streams. This allows for a shift in perspective. While Schumpeter, and many others following in his footsteps, focused on the entrepreneur as the innovator and main element of the process, for Tarde (2009) it is inventions which are the central 'driver' of social development. In this context, the idea of a social innovation ecosystem helps to overcome a strict actor-centred approach and the strong concentration on the social entrepreneur as the key agent of change. The view on the environment in which social innovations are diffused opens up the perspective on different dimensions.

To cover the whole environment of SI, it is hence considered part of an ecosystem rather than part of an organisational framework that only contains competitors, suppliers and customers (Bloom and Dees, 2008). In order to better understand why only few inventions prove to be successful and sustainable and a multitude of inventions perish and disappear, we need to understand the ecosystem as the comprehensive organisational, institutional and cultural setting in which the SI is embedded. In this setting, actors like entrepreneurs and others play specific roles and try to fulfil assigned or self-assigned functions - but they themselves do not act in an entirely independent way, but according to the expectations they are confronted with. In this perspective, and this is the second point to make, it is not only supporting factors that should be regarded as the "ecosystem" (like in early approaches of the "incubator" thinking), but the ecosystems also holds hindering and obstructive influences for an innovation. Here, one of the important factors of support/obstruction is whether the new idea, and with it the supporting initiative, can swim with the tide of a whole stream of similar new ideas and innovations, collectively contributing to changing mind-sets and societal change, or not. This article pleads for a context sensitive understanding of an "ecosystem" that is able to identify, analyse and connect both drivers and barriers social innovation initiatives may encounter, no matter by which societal sector(s) they are promoted.

\section{Four layers of social innovation ecosystems}

In order to understand the complex environment in which social innovations are created, develop and flourish on the one hand and take effect or perish on the other hand, we have developed the model of an ecosystem with four analytical layers. Each layer describes its one distinct context of drivers and barriers, factors supporting or impeding social innovation. While this model describes the ecosystem of social innovation in general, it can also be applied to social innovations for vulnerable groups.

1. Context of roles: On a "role context", socio-demographic factors and roles of social innovation stakeholders and beneficiaries are identified. This includes these actors' political and social attitudes, motivations, socialization, self-concepts, image, capabilities and skills.

2. Context of functions: A "context of functions" comprises factors such as management procedures, business and governance models. Questions such as how different actors are interlinked and collaborate, how they adjust their roles in a wider network context and how the network is governed are relevant on this layer.

3. Context of structures: This context delivers insights into constraints and path dependencies because of existing institutions, economic, political and technological imperatives. These define factual boundaries or, on a positive notion, the contingency of social innovation. This can be the setup of a city administration, restricting what can be achieved on the role and functional context, or the political orientation of the government. Technological infrastructures (not) available and financial resources to be allocated also build the structural context.

4. Context of norms: Here, the societal framework conditions and challenges come into play. The normative context shows professional and ethical standards, historical and legal conditions, codes and other accepted social standards. What social innovation initiatives are legally allowed to do is defined on this layer, as well as which professional standards actors such as politicians, consultants, IT specialists or other parties involved will have. 
These contexts, in synopsis, build up an ecosystem of four layers of (digital) social innovation. With this structure and its inherent characteristics of closeness within the contexts and simultaneous permeability, it resembles a model Weischenberg (1990) introduced in communication sciences. He distinguishes different contexts of news production and thereby guides research on the diffusion of news and how and if they make it into mass media. He emphasizes the strong contextsensitivity of the production of "news" and differentiates between four contextual layers, arranging them in form of an "onion" in order to symbolize the interdependency and permeability of those contexts: "Actors" (the innermost layer; assembling socio-demographic features of the media actor, e.g. journalist), "functions" (the second layer; focusing on the process in which media are produced), "structures" (the third layer; collecting economic, political, organizational and technological imperatives) and "norms" (the outer layer; the legal and policy context). The following figure shows a possible model which transfers Weischenberg's approach to social innovation ecosystems.

Figure 1: The "Onion”: Four contextual layers of social innovation ecosystems

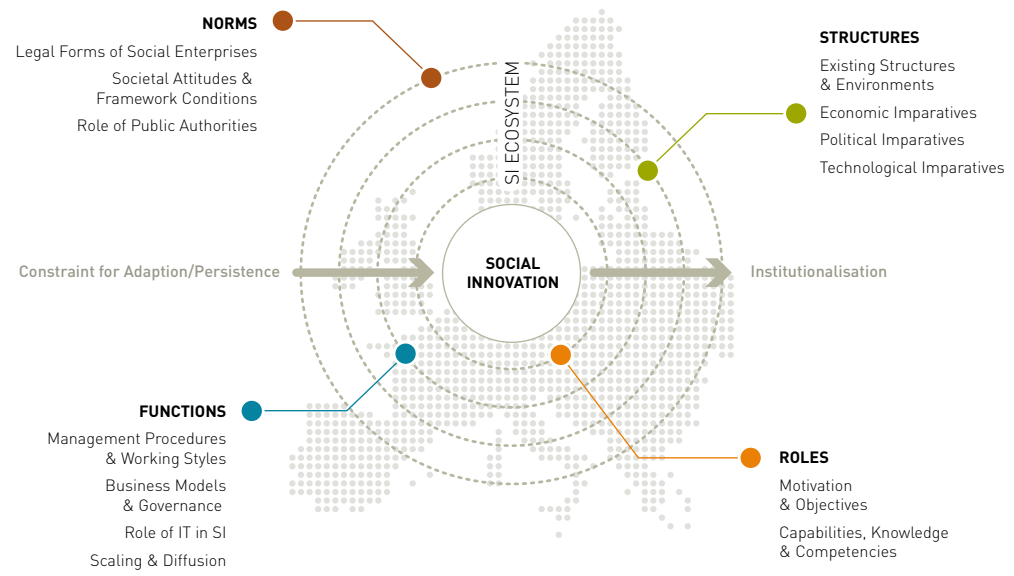

Source: SIMPACT, 2016.

This onion model, in both perspectives, helps to identify and analyse drivers and barriers both within and between the contexts. Every initiative is operating within - partly visible, partly invisible framework conditions forming this multi-layered social innovation ecosystem. Some factors are conducive to a good development or scaling of the innovation, some may be influenced and changed for the better, some have to be accepted.

\section{Analysis of SIMPACT case studies}

In order to create a fundamental understanding of the „onion"-model of drivers and barriers, it is applied to two case studies conducted within the SIMPACT project. Chapter 4.1 presents the "Discovering Hands" organisation which trains visually impaired women to discover breast cancer. In the following, the "Aspire" company is introduced, a catalogue-delivery company employing people without a permanent residency.

\section{Discovering Hands}

\section{Basic Idea and Implementation}

Discovering Hands ${ }^{\circledR}$ is an organisation which trains woman with limitations to their visual abilities or blindness to use their tactile sense to perform breast palpation for breast cancer prevention, thus developing the new occupational profile of Medical Tactile Examiners (MTEs). It has been developed by Dr Frank Hoffmann, a resident gynaecologist in the region of Duisburg, North Rhine Westphalia. As a young doctor, he took over his medical office from a colleague and soon started a merger with other gynaecologists in the region resulting in a network of practices with nine medical specialists in four locations (Ashoka, 2010; FASE, 2014). In 2001 he founded the "Quality Circle of Gynaecologists in Duisburg, a round table guaranteeing standardized quality control in the region of Duisburg, and led it until 2009" (Ashoka, 2010). Also in 2009, "Frank set up 
a service company to outsource the administrative and IT work of his joint medical practice. This forprofit venture is one of the first of its kind and a pioneering model of how medical practices could become more efficient and fit for future changes in the health care system" (ibid.).

He developed the concept of Discovering Hands after a change in breast cancer prevention policies in Germany. He deemed the medical care for women with the risk of breast cancer as insufficient. In 2004, Hoffmann came up with the idea to utilize the special tactile senses of visually impaired women in medical diagnostics (FASE, 2014). MTEs generate more accurate results because of their especially trained tactile sense and also because they spend more time with patients than a gynaecologist does. In order to enable MTEs to conduct the examinations, Hoffmann developed a standardized system for the women to perform the tests based on braille strips. To qualify for their task, MTEs undergo a nine-months training developed by Discovering Hands. The training is funded by public means as vocational rehabilitation scheme (FASE, 2014). After their training, MTEs can be employed by resident gynaecologists or hospitals or can work for different employers on a freelance basis (Discovering Hands, n.d.a). An increasing number of German health care insurances cover the examinations by MTEs.

\section{Organisational Structure (and support system)}

As a hybrid business model, Discovering Hands is based on three pillars:

The discovering hands gUG is a non-profit branch of Discovering Hands. It holds the concept's usage and trademark rights. Furthermore, it is responsible for its further development and global penetration, further development of the curriculum, academic validation and education for MTEs and gynaecologists.

The discovering hands service $\mathbf{G m b H}$ (limited liability company) is the for-profit part and the operative business entity of the organizational structure. This branch is responsible for the production and distribution of the orientation strips and acts as contractual partner of health insurances and doctors (FASE, 2014; Discovering Hands, 2012).

The third part of the organizational structure is the so-called MTE Forum, a registered association according to German law which is also a non-profit entity. Its tasks are the representation of interests and the support of the MTEs (FASE, 2014; Discovering Hands, 2012).

Discovering Hands received and receives support by several stakeholders, including
BonVenture, a social venture capital fund, the Financing Agency for Social Entrepreneurship (FASE), as well as several foundations, pharmaceutical companies and law firms working on a pro-bono basis, especially when setting up the business structure (FASE, 2014). Discovering Hands was also to a great extent supported by Ashoka ${ }^{1}$ as founder Frank Hoffmann was elected Ashoka fellow in 2010.

Whereas the MTE Forum is mainly funded by private donations, the non-profit gUG receives support from several foundations and the profits generated by the $\mathrm{GmbH}$ as "the generated profits will be exclusively invested in the expansion of the business or distributed to the non-profit holding company discovering hands ${ }^{\circledR}$ gUG” (FASE, 2014: 16). Also "all further stakeholders (investors) commit to transfer any dividends (if not reinvested) to non-profit entities" (ibid.). The transfer of the profits from the $\mathrm{GmbH}$ to the gUG is ensured as the gUG functions as 100 per cent shareholder of the $\mathrm{GmbH}$. This organizational structure ensures the charitable orientation on both sides of the Discovering Hands complex (Discovering Hands, 2012). The goal is for Discovering Hands to become "a self-sustaining financial system" (FASE, 2014: 16).

\section{Scaling}

The efforts for scaling Discovering Hands include the goals to incorporate the profession of MTEs as recognized occupation with designated education, a set-up of local centres for breast health and the implementation of the concept in other countries. For that purpose, a social franchising system was developed with professional assistance by a specialized franchise consultancy. The franchisees are selected regarding defined criteria (FASE, 2014). 2014 the expansion to Austria took place, with the school of the Blind- and Visually Impaired People's Association of Austria. This expansion was also supported by several foundations (ibid.). A pilot project in Columbia is currently running (Discovering Hands, 2015).

\section{Aspire}

\section{Basic Idea and Implementation}

Aspire was a catalogue delivery firm employing homeless people aiming at their rehabilitation. It was founded in the late 1990s by Paul Harrod and Mark Richardson, two recent Oxford graduates.

\footnotetext{
1 Ashoka is an organisation fostering the development of social entrepreneurship
} 
During their time in Oxford they had been volunteering "at various charities for the homeless where they concluded that many programs fail because they focus on the symptoms of homelessness rather than on its root causes" (Tracey and Jarvis, 2006) and found that many approaches addressing homelessness failed. Their approach was to tackle the problem at its core by providing employment to homeless people.

"The business model [...] was based upon established and successful British for-profit household catalogue delivery firms" (Tracey et al., 2010), as Harrod had been working for such a firm during his studies. Therefore, he was familiar with the catalogue business as well as with the skills required as a door-to-door salesman. The business worked as follows: The employees were recruited from the homeless community in Bristol. They

were responsible for posting the catalogues through letterboxes and then collecting the resulting orders from around the city. Once the orders had been collected, Harrod and Richardson put the orders together and delivered them to households each weekday evening. Time was also allocated to provide support to employees in the form of literacy and numeracy classes and help with other basic employment skills. (Tracey et al., 2010: 8)

As the founders considered "commission-based pay unfair, they offered employees a flat pay rate, irrespective of sales" (Tracey and Jarvis, 2006: 67). Thus, the employees were given the tools to build capabilities useful for re-building their lives and are also a new perspective on the employment market. The catalogue itself was designed and set up by Harrod and Richardson. As the business was mainly run and supported by volunteers, it was able to work self-sustainingly.

\section{Organisational structure}

Aspire was founded with a $£ 5,000$ grant from the Prince's Trust as well as donations from local businesses and residents. Promotion by local media helped boosting the sales: "Thirteen months after it was launched, Aspire had attracted 4,000 regular customers, had a turnover of about $£ 150,000$, and employed 15 staff. The business began to attract considerable interest from all quarters" (CaulierGrice, 2008). Due to the success, Harrod and Richardson invited Terrance Roslyn Smith who previously "had been involved in a number of social enterprise projects" (Tracey and Jarvis, 2006: 67) to join the management team by the end of the year 1999 in order to plan Aspire's further development. Early in the year 2000, the three men decided Aspire could expand into other cities in the United Kingdom; they considered franchising to be the quickest and most cost-effective way to do so. Between September 2000 and September 2001, nine franchises were opened throughout the UK (Tracey et al., 2010). The franchises were intended to work the same way as the original venture in Bristol. After having received an investment of $£ 400,000$, a new company - Aspire Group - was founded. The Group was in charge of managing the catalogue company, designing the catalogue and sourcing the goods while the franchises were operating locally, distributing the catalogues, delivering orders and supervising and training the homeless employees. Most of the franchises were embedded within existing charitable organisations which had experiences working with homeless people but only four had experience in the field of managing a business or a social enterprise.

"During Harrod's time as CEO, Aspire established 12 franchises, taking 300 homeless people off the streets as sales reached $£ 1.3$ million" (Caulier-Grice, 2008). Aspire was praised by press and politics; Prime Minister Tony Blair as well as HRH Prince Charles expressed their appreciation for the business. "The government started to look at Aspire as a potential model to combat social exclusion" (ibid.).

\section{Failure}

Soon after the franchises started, the Group as well as the franchises were facing financial difficulties which Tracey and Jarvis (2006) ascribe to the fact that "the narrow range of products attracted only a narrow range of customers" (ibid.: 68). Furthermore, several employees were facing personal problems like drug abuse and poor mental health conditions and were therefore not deemed to be a reliable workforce, which was a danger to the business' success. The franchisees found themselves in a fundamental conflict: Mostly having a background in the field of social work, they were dedicated to the mission of rehabilitating their homeless employees, which were also their clients at the same time. However, when employees were absent and not able to work, the franchisees were not able to maintain their business operations and thus to fulfil their economic goals, while, at the same time having the expenditures of paying the salaries. These difficulties endangered the business success to a great extent and also hurt the franchisees morale when they were forced to dismiss some of their employees against their own convictions. Furthermore, they were lacking 
support by their franchisor. Aspire Group did only provide a minimal training and also did not offer guidance regarding the business operations.

As result of the financial struggles, two franchises had to be closed by the end of 2001 . Despite the difficulties, Harrod was convinced that the business model would succeed. In the middle of 2002 , he managed to gain another loan of $£ 250,000$ by a group of investors to stabilise the business. Besides that, Aspire tried changing the business model, focusing on financial survival whereas the franchisees' priorities remained on supporting their homeless employees. The balance between business and social work placed the business in a dilemma, for example when the Group enacted on the investors' insistence to run the catalogue business only during the months before Christmas and Easter, which meant that the franchisees were forced to give up their primary goal of rehabilitating homeless people by a constant employment as the new concept demanded temporary, seasonal employment. To ensure their survival, many franchises tried to establish secondary businesses, like bicycle repair shops, window cleaning services and furniture manufacturing.

The balance between business and social work placed the business in a dilemma. All measures to save the company did not succeed: Harrod stepped down as a CEO in September 2003 and by the end of the year, Aspire was effectively bankrupt (Tracey and Jarvis, 2006).

\section{Applying the model: Drivers and barriers for social innovation}

Although the two cases have some characteristics in common (combining non-profit and for-profit elements, diffusion by franchising), they differ in many aspects. Obviously, whereas Discovering Hands succeeded, Aspire failed. ${ }^{2}$ While the concrete reasons for success and failure are manifold, complex and difficult to reproduce, some crucial points of their dynamics will be elaborated in the following, highlighting the drivers and barriers of the cases and assigning them to the four contextual layers of the "onion model" of social innovation ecosystems.

Gynaecologist Frank Hoffmann, founder of Discovering Hands, has developed a quality circle

\footnotetext{
${ }^{2}$ Regarding Terstriep et al. (2015), failure in the context of SI can be understood not only as business failure but also as mission failure when mission drift is not opposed. Thus, an SI can fail financially while being successful in its mission for the benefit of its target group and vice versa. However, Aspire failed regarding both the sustainability of its business and its mission.
}

in his hometown and has experience in promoting organizational innovation in his company. Being an experienced networker and manager, he was able to use his skills and knowledge to identify a need and to develop and implement a solution. Harrod and Richardson had made some experiences by volunteering to work with homeless people. Harrod had been working as a door-to-door salesman during his studies. Nevertheless, they were relatively unexperienced in social work and management, which in their perspective e.g. had led to the underestimation of the clients' psychological and health problems. However, Harrod convinced potential investors who then provided grants to the start-up business. These are some examples of the two cases' differences in the role context. Again, these findings do not sufficiently explain the developments the two initiatives have taken, but they provide a glimpse of the overall picture. The social innovation is always embedded into the innovators' social reality, his / her objectives motivation, socio-demographic features, competences and opinions. The "context of roles" can be understood as the "opus operatum" aspect of Bourdieu's (1983) notion of "habitus".

Discovering Hands' operation mode is based on different pillars. Beneficiaries are on the one hand women with an increased risk of breast cancer and on the other hand blind women gaining a unique employment opportunity where their limitation of sight is perceived a capability instead. Thus, also the funding is provided by different sources: The trainings for the MTEs are covered by VET funding schemes for people with disabilities and the training centres are paying a license fee to Discovering Hands. The gynaecologists employing METs are buying the orientation strips for the examinations and the examination itself is covered by health care insurances. From the organizational perspective, the SI is operating on a hybrid structure ensuring the economic stability as well as vision and operational orientation. In contrast, Aspire was strictly relying on its own profits. Employees were offered a flat pay rate, which turned out to be problematic when reliability issues with the staff came up. Additionally, there were no therapeutic efforts to meet health problems which have negatively impacted productivity. The work flow of the business was depending to a large extent on volunteers. Despite such potential soft spots in the concept, the business was performing well at first. However, in retrospect, the efforts of scaling this business model by franchising in a relatively early stage of development revealed those soft spots. Management principles of scaling, governance approaches, and the volunteers network Aspire 
relied upon shape and potentially limit an initiative's development on the functional layer, which connects to Bourdieu's (1983) notion of "Modus Operandi".

Another promotive aspect for both initiatives can be seen in the support they gained. Discovering Hands was supported in its development by many different stakeholders, among them Ashoka. There was advice from a professional consultancy when it came to scaling the model by franchising. As the franchisees are selected regarding defined quality criteria, the risk of failure is minimized. Furthermore, Discovering Hands utilizes the existing structures in its favour, for example when it comes to funding by different governmental and health care entities. Aspire convinced investors of their business model in order to acquire a sufficient amount of grants. This is not only a driver but a principal prerequisite. Nevertheless, it also turned out to be a barrier when they were approved a loan, although the business model had shown some weaknesses and Aspire was facing its decline. Scepticism on the investors' part could have decelerated the decline or fostered Aspire in adapting its business model. However, the collaboration with its franchisees was not successful: There was no defined and shared set of management knowledge, skills and working principles Aspire could have insisted upon. In addition, the goals were steadily drifting apart, obstructing an efficient collaboration. These examples are part of the structural context of an initiative. No matter how "new" or "radical" a social innovation may appear, it always faces constraints and path dependencies because of existing solutions, economic, political and technological imperatives which may turn out supportive or hindering.

The foundation of Discovering Hands is rooted in the changing breast cancer prevention policies in Germany. The founder deemed the medical care for women with the risk of breast cancer as insufficient and thus was developing a solution himself. Due to his experience in networking and quality management he was able to estimate the structure of the health care system he was operating in as well as the nature of its underlying norms which enabled him to plan his approach in accordance. Thus, the SI is to a great extent influenced by the political and societal landscape it is operating in. Furthermore, it also takes influence on that landscape in reverse by challenging the medical system, introducing a new profession (blind people with occupational training) and changing the regulations of health care insurances as an increasing number of insurances is willing to cover the costs for the breast examinations. It raises the question of competences and responsibilities between this new and the existing profession of gynaecologists. A promoting factor for Aspire can be seen in the support by the media and politicians, including the then Prime Minister Tony Blair. This can be ascribed to the nature of the British welfare system which is characterized by a high selfresponsibility of individuals and a broad deregulation. The concept of Aspire as a selfsustaining, private organisation activating a marginalised group to (re-)enter the employment market and therewith getting included in the society was to a great extent in accordance with the goals and the orientation of the New Labour government. Aspire's initial success was interpreted as a validation of New Labour's social policy and an encouraging signal to comparable organisations. Therefore, political support can be ascribed to the good publicity for the governmental welfare strategy. This support in turn facilitated financial support by investors. The normative context to which these drivers and barriers belong comprises the "intangible" layer of societal codes - officially codified or unofficially accepted - that influence the initiative. These can be laws, norms, standards, codes of conduct or ethical expectations. As far as the relation of social innovation to social change is concerned (cf. Howaldt, Kopp and Schwarz, 2015), such legal and ethical norms and derived mutual social expectations do not only influence and constrain the development of an initiative. In a medium to long term, social innovations can also affect and alter these societal norms.

\section{Conclusion}

These drivers and barriers presented and assigned to the four levels of social innovation ecosystems are surely not the only reasons for the different pathways the two initiatives took. However, in the SIMPACT case studies, they were considered important factors for the overall development of Discovering Hands and Aspire. The four layers of the model can be considered separately, which helps to structure and analyze similar intervening factors in groups. In a following step, these factors can also be analyzed more deeply by elaborating on their interrelations and thereby visualizing the ecosystemic complexity as a whole. The "onion model" describes the multi-layered selection processes within an ecosystem of social innovation. It distinguishes itself by differentiating four levels ("onion layers") of the ecosystem surrounding the SI. Thus, it emphasizes the embeddedness of SI in its societal context. More specifically, by 
emphasizing the ambivalence of all social innovations, it sheds light on why drivers and barriers emerge for specific initiatives - again, on different, yet connected layers.

The "onion" metaphor allows for two directions of "cutting" its layers as an interpretative process: As illustrated in the analysis of the case studies, there are several factors on every onion layer influencing the SI in a fostering ("driver") or hindering ("barrier") kind. Thus, as a transversal analytical process the "onion" could be "cut" from the outer layers to the inner core. This perspective reflects the process of constraints and persistence. "Existing" (see above) norms, institutions and social practices strive to prevail themselves against the innovation. This is the force that innovators experience when shaking long established practices: They see laws and norms restraining their innovativeness, institutions rejecting their support and staying in what Terstriep et al. (2015) call "silo thinking" and actors arguing that something has to been done in the "old ways". Constraints and persistences strive to suppress the innovation from macro to micro level and so reflect the process of cutting the onion from outside to the core. The same processes are also valid when it comes to factors promotive for the development of SI.

However, the SI may in turn also have influence on its surrounding ecosystem: If seeing the onion from the inner core to the outward layers (the "growing" process of an onion), the four layers can be understood as a process of growing institutionalisation. The innovation (in its "intangible" form) permeates through persons (the context of roles), through those persons' doing (the context of function) and through organisations (the context of structures). Some innovations even influence the context of norms, for example by influencing what is considered as "ethical" or "right". For example, Discovering Hands takes influence on the layer of norms by challenging the medical system, introducing a new profession (blind people with occupational training) and changing the regulations of health care insurances as an increasing number of insurances is willing to cover the costs for the breast examinations. This "growing" process reflects what Howaldt/Schwarz call "socially accepted and diffused" (2010: 21). In this notion, a social invention only becomes a social innovation by being actually used, spread and turned into social practice. The onion model therefore offers a model of tracing the transformation from an invention into a social practice through its different layers with a growing institutionalisation and societal diffusion. In reality of course, such growth across different layers is not linear, but characterized by constant feedback loops when objectives are challenged, new competencies are developed or cooperational structures are forged as a result of learning, in order to better sustain and institutionalize the innovation. This observation accredits the insight that innovations spread through people's doing. In other words: "In the realm of the social, everything takes place as invention and imitation, with imitation forming the rivers and inventions the mountains" (Tarde, 2009: 26, cited from: Howaldt et al., 2014: 6).

A social innovation initiative, and especially a bundle of such initiatives in a common practice field, is not only influenced by its surrounding ecosystem, but it may also influence its ecosystem itself. The onion model is capable of illustrating that kind of reciprocal interaction. Another outstanding characteristic of the model can be seen in the missing need for a dualistic classification of drivers and barriers for SI. The assessment of fostering and hindering factors in an SI's ecosystem is often characterized by an uncertainty how to define drivers and barriers and their interconnections. Therefore, a missing driver can be a barrier and vice versa. The onion is not dependent on such a dualistic classification as it only displays influential factors in both directions (cutting the onion from outside to the core or vice versa).

Especially the last characteristic makes the model suitable for counselling in the field of social entrepreneurship as well as on the policy level. In the context of the SIMPACT project, a so-called Context Understanding Guide was developed based on the onion model (Pelka and Markmann, 2015). The guide consists of a structured collection of questions helping social entrepreneurs, policy makers and other stakeholders involved assess the situation and context of the respective SI. The questions cover aspects regarding the different onion layers which can be relevant for the development of the SI in the context of its ecosystem. As drivers and barriers are hard to define and are, to a great extent, dependent on the single respective innovation, the ambition of this guide is not to pinpoint drivers and barriers by itself but to support the actor in identifying possible drivers and barriers (ibid.).

Due to its flexibility and multi-directionality the onion model can be used as an orientation for the application of further instruments or tools or may as well be developed further and evolve into an instrument of assessment and planning itself. 


\section{References}

Arthur, B. (2009). The Nature of Technology. New York: Free Press.

Ashoka (2010). "Frank Hoffmann”. Accessed 11 November 2015. http://germany.ashoka.org/fellow/frankhoffmann

Bason, C. (2010). Leading public sector innovation, Bristol: Policy Press.

Bekkers, V.; Edelenbos, J. and Steijn, B. (eds.) (2011). Innovation in the Public Sector: Linking Capacity and Leadership, Governance and Public Management Series. Basingstoke: Palgrave Macmillan.

Bekkers, V. and Homburg, V. (2005). "E-Government as an Information Ecology", In: V. Bekkers and V. Homburg (eds.), The Information Ecology of E-Government (pp. 1-19). Amsterdam: IOS Press.

Bloom, P. and Dees, G. (2008). "Cultivate your Ecosystem." Stanford Social Innovation Review 6 (1), 47-53.

Bourdieu, P. (1983). "Ökonomisches Kapital, kulturelles Kapital, soziales Kapital“". In: R. Kreckel (ed.). Soziale Ungleichheiten (pp. 183-198). Göttingen: Schwartz.

Carayannis, E. G. and Campbell, D. F. J. (2012). "Mode 3 Knowledge Production in Quadruple Helix Innovation Systems", Springer Briefs in Business, 7, 1-64.

Castells, M. (1996). The rise of the network society. Cambridge: Blackwell.

Caulier-Grice, J. (2008). "Aspire Group Ltd. Social innovation exchange: Case study". Accessed 11 November 2015. http://www.socialinnovationexchange.org/categories/read/aspire-group-ltd

Discovering Hands (2012). "Discovering Hands: Jahresbericht 2012". Accessed 12 November 2015. http://www.social-reporting-

standard.de/fileadmin/redaktion/Anwenderberichte/Herausragende_Anwenderberichte/Nach_SRS 2012 12012 discovering hands.pdf

- (2015). "Discovering Hands: English version". Accessed 12 November 2015. http://www.discoveringhands.de/start/english-version.html

- (2015). "Pilotprojekt in Kolumbien: Die Teilnehmerinnen für den ersten discovering hands ${ }^{\circledR}$ - Kurs stehen fest". Accessed 12 November 2015. http://www.discovering-hands.de/news/209-pilotprojekt-inkolumbien-die-teilnehmerinnen-fuer-den-ersten-discovering-hands-kurs-sind-bekannt.html

European Anti-Poverty Network (2016). "The contribution of meaningful Social Innovation to reducing poverty and social exclusion in Europe, EAPN booklet”. Accessed 11 August 2016. http://www.eapn.eu/wpcontent/uploads/2016/03/2016-EAPN-Social-Innovation-Booklet.pdf

European Commission (2013). COMMUNICATION FROM THE COMMISSION TO THE EUROPEAN PARLIAMENT, THE COUNCIL, THE EUROPEAN ECONOMIC AND SOCIAL COMMITTEE AND THE COMMITTEE OF THE REGIONS Towards Social Investment for Growth and Cohesion including implementing the European Social Fund 2014-2020/*COM/2013/083 final *. Accessed 11 August 2016. lex.europa.eu/LexUriServ/LexUriServ.do?uri=COM:2013:0083:FIN:EN:HTML

FASE (Finanzierungsagentur für Social Entrepreneurship) (2014). "Case Study Social Entrepreneurship: Scaling and Financing of a Social Innovation Business Model, Social Impact, Financing, Social Franchising: Discovering Hands". Accessed 12 November 2015. http://social-enterprisefinance.eu/sites/default/files/140907 Case Study Discovering Hands English.pdf

Hansson, J.; Björk, F.; Lundborg, D. and Olofsson, L.-E. (2014). An Ecosystem for Social Innovation in Sweden: A strategic research and innovation agenda. Lund: Lund University.

Howaldt, J. and Schwarz, M. (2010). "Social Innovation: Concepts, Research Fields and International Trends". In K. Henning and F. Hees (eds.) Studies for Innovation in a Modern Working Environment International Monitoring, Vol. 5. Department of Information Management in Mech. Engineering. Center for Learning and Knowledge Management Ass. Institute for Management Cybernetics e.V. IMA/ZLW \& IfU - RWTH Aachen University, Aachen. Accessed 13 September 2015. http://www.internationalmonitoring.com/fileadmin/Downloads/Trendstudien/Trends V2/IMOMAG\%20Howaldt final mit cover.pdf

Howaldt, J.; Butzin, A.; Domanski, D. and Kaletka, C. (2014). "Theoretical Approaches to Social Innovation A Critical Literature Review", A deliverable of the project: 'Social Innovation: Driving Force of Social Change' (SI-DRIVE). Dortmund: Sozialforschungsstelle.

Howaldt, J.; Schröder, A.; Kaletka, C.; Rehfeld, D. and Terstriep, J. (2016). „Mapping the world of social innovation. A global comparative analysis across sectors and world regions". Dortmund: Sozialforschungsstelle. DOI: http://dx.doi.org/10.17877/DE290R-17198 
Howaldt, J.; Kopp, R. and Schwarz, M. (2015). "Social innovations as drivers of social change: Exploring Tarde's contribution to social innovation theory building", In: A. Nicholls; A.J. Simon and M. Gabriel (eds.) New frontiers in social innovation research (pp. 29-51). Basingstoke: Palgrave Macmillan.

Kaletka, C. and Pelka, B. (2015). "(Digital) Social Innovation through Public Internet Access Points”. In: M. Antona and C. Stephanidis (eds.) Universal Access in Human-Computer Inter-action. Access to Today's Technologies, UAHCI 2015, Part I, LNCS 9175 (pp. 201-212) Cham: Springer

Koh, H.; Hegde, N. and Karamchandani, A. (2014). "Beyond the Pioneer: Getting inclusive industries to scale", Deloitte Touche Tohmatsu India Private Ltd (DTTIPL). Accessed 20 August 2016. http://www.beyondthepioneer.org/wp-content/themes/monitor/Beyond-the-Pioneer-Report.pdf

Levi-Strauss, C. (1962). La pensée sauvage. Paris: Librarier Plon.

Miller, P., and Stacey, J. (2014). "Good Incubation: The craft of supporting early-stage social ventures", London: $\quad$ NESTA. $\quad$ Accessed $20 \quad$ August 2016 http://www.nesta.org.uk/sites/default/files/good incubation wv.pdf

Osborne, S. and Brown, L. (2011). "Innovation, public policy and public services delivery in the UK: the word that would be king", Public Administration, 89 (4), 1335-1350.

Pelka, B. and Markmann, M. (2015). "Criteria \& Recommendations to Strengthen Social Innovation", Deliverable D4.2 of the project 'Boosting the Impact of SI in Europe through Economic Underpinnings' (SIMPACT), European Commission - 7th Framework Programme. Brussels: European Commission, DG Research \& Innovation.

Phills, J. A.; Deiglmeier, K. and Miller, D. T. (2008). „Rediscovering social innovation”, Stanford Social Innovation Review, 6 (4), 34-43.

Pol, E. and Ville, S. (2009). "Social innovation: Buzz word or enduring term?", The Journal of SocioEconomics, 38, 878-885.

Porter, M. E. (1985). The Competitive Advantage: Creating and Sustaining Superior Performance. New York: Free Press.

Rehfeld, D., Terstriep, J.; Welschhoff, J. and Alijani, S. (2015). “Comparative Report on Social Innovation Framework". Deliverable D1.1 of the project 'Boosting the Impact of SI in Europe through Economic Underpinnings' (SIMPACT), European Commission - 7th Framework Programme. Brussels: European Commission, DG Research \& Innovation.

Rogers, E. (1995). Diffusion of Innovations. New York: Free Press.

Rüede, D. and Lurtz, K. (2012). "Mapping the various meanings of social innovation: Towards a differentiated understanding of an emerging concept". EBS Business School Research Paper No. 12-03. Accessed 13 July 2015 . http://ssrn.com/abstract $=2091039$

Sgaragli, F. (ed.) (2014), Enabling social innovation ecosystems for community-led territorial development. Quaderni della Fondazione Giacomo Brodolini, "Studi e ricerche" series, 49. Fondazione Giacomo $\begin{array}{lllll}\text { Brodolini, } & \text { Rome. } & \text { Accessed } & 11 & \text { August }\end{array}$ http://www.fondazionebrodolini.it/sites/default/files/pubblicazioni/file/q49 $0 . p d f$

Terstriep, J.; Kleverbeck, M.; Deserti, A. and Rizzo, F. (2015). "Comparative Report on Social Innovation across Europe", Deliverable D3.2 of the project 'Boosting the Impact of SI in Europe through Economic Underpinnings' (SIMPACT), European Commission - 7th Framework Programme. Brussels: European Commission, DG Research \& Innovation.

Tracey, P. and Jarvis, O. (2006). "An Enterprising Failure: Why a promising social franchise collapsed". Stanford Social Innovation Review, 4(1), 66-70.

Tracey, P.; Philips, N. and Jarvis, O. (2010). "Bridging Institutional Entrepreneurship and the Creation of New Organizational Forms: A Multilevel Model”. Organization Science, 22(1), 66-80.

Unceta, A.; Castro-Spila, J. and García Fronti, J. (2016). "Social innovation indicators". Innovation: The European Journal of Social Science Research, 29(2): 192-204.

Wallin, S. (2010). "The co-evolvement in local development - From the triple to the quadruple helix model", Paper presented at Triple Helix VIII, Madrid. Accessed 20 August 2016 http://www.leydesdorff.net/th8/TRIPLE\%20HELIX\%20$\% 20$ VIII\%20CONFERENCE/PROCEEDINGS/0110 Wallin Sirkku O104/triple\%20helix\%20Wallin\%20final.pdf

Weischenberg, S. (1990). "Das 'Paradigma Journalistik'”, Publizistik, 35(1), 45-61.

Westley, F.; Zimmerman, B. and Patton, M. (2006). Getting to Maybe: How the World is Changed. Toronto: Random House of Canada. 